\title{
LLC Converter Based PV Water Pumping System With Enhanced User Safety Approach
}

\author{
Anuradha Tomar, Netaji Subhas University of Technology, Delhi, India
}

\begin{abstract}
In this paper, the LLC resonant converter-based photovoltaic (PV) water pumping is proposed. PV water pumping is proved as a promising solution in remote areas where electricity is still a major concern and thus helpful in providing drinkable water, supporting irrigation activities as a selfsufficient system. Commercially available PV-based water pumping system consists of a non-isolated DC-DC converter which is suitable for low power applications however results in a less safe operating environment for humans. In the case of PV based water pumping systems, the safety of humans should be the main concern, as these systems are normally being operated by farmers, their families, and it may be possible that they are not that aware of operational hazards. Therefore, this paper attempts to present an LLC converter-based PV water pumping system, considering human safety as a major concern. The proposed system is simulated in MATLAB/Simulink environment, and results show that the proposed system configuration has no adverse impact on system efficiency, and it enhances the safety of operating personals. Presented results can be further exploited for hardware verification as the future scope of this work.
\end{abstract}

\section{KEYWORDS}

Brushless DC Motor (BLDC), Irrigation, LLC DC-DC Converter, Photovoltaic (PV), Solar, Water Pumping

\section{INTRODUCTION}

The application of photovoltaic (PV) systems for extracting water from the ground is a promising application to provide/supply water for irrigation, drinking and to fulfill the other daily basic needs in remote areas that are still struggling for electricity. Designed PV based water pumping system should be energy efficient, low cost, and robust with less maintenance requirement and most importantly should be safe enough as to be operated by common personal without need of any additional piece of training or skills. Also, in the case of PV water pumping systems, many times it may possible that family members of farmers may operate the system, therefore human safety should be considered as a major concern.

Authors (R. Kumar, 2014; V. Gali, 2016; P. Vtas, 2017) proposed a buck-boost converter-based PV water pumping system intending to reduce the required number of components and achieving overall good operational efficiency. The performance of the Zeta DC-DC converter for the PV water pumping system is illustrated in (R. Kumar, 2016). In the proposed configuration Zeta converter is responsible for global MPPT. The non-inverting output of SEPIC based DC-DC converter helps in

\section{DOI: 10.4018/IJAEIS.20211001.oa2}

This article published as an Open Access article distributed under the terms of the Creative Commons Attribution License (http://creativecommons.org/licenses/by/4.0/) which permits unrestricted use, distribution, and production in any medium, provided the author of the original work and original publication source are properly credited. 
a smooth, jerk-free run of DC motor and thus results in an increased life of DC motor. A PV based water pumping system consists of a SEPIC converter operating in buck-boost mode was presented in (R. Kumar, 2014). Application of SEPIC topology results in less number of components, simpler gate driver circuit along with low input current pulsation. Further authors in (T. Jayaraj, 2019) illustrated a KY converter fed solar water pumping system, which aims to reduce the voltage ripples along with a high transient response.

In order to reduce the complexity, cost and further optimizing the power output, authors (B. Singh, 2018) proposed a SE-CuCC (SEPIC-Cuk) converter, which was developed as a combination of Cuk and SEPIC converter, considering the advantages of both. The developed system is specially designed for applications in rural and remote areas. SEPIC-Cuk converter acts as a power optimizer between the PV system and the switched reluctance motor (SRM). Application of Luo DC-DC converter to implement MPPT operation in a PV based water pumping system was investigated in (A. R. Anjana, 2017). Implementation of Luo converter in such systems results in reduced output current ripples and also enables the extraction of enhanced PV energy by operating system's PV modules at MPPT.

The concept of an integrated quadratic boost converter was applied for the PV water pumping system, taking advantage of high static voltage gain. Isolated Zeta and Quadratic boost converters (Meghna, 2018) were connected in a cascaded fashion to a PV system, formed of PV arrays connected in parallel and thus resulting in a PV system with low output voltage. Further, with the objective of efficient utilization of solar panels, authors in (K. Shah, 2017) demonstrated the operation of quadratic boost converter for MPPT operation of the system considering variations in irradiation patterns and ambient temperature values.

A single-stage, induction motor based solar water pumping system without any storage was proposed in (J. V. M. Caracas, 2014). A new converter topology derived from the concept of a two-inductor boost converter (TIBC) also known as the current-fed multi-resonant converter is developed. The proposed system configuration has the advantages of the reduced number of system stages along with the benefit of using an induction motor instead of DC motor in the system. A new modified central switch operated DC-DC converter-based PV irrigation system fed by SRM driven water pump was proposed (A. K. Mishra, 2017). The advantage of the proposed system was that it can extract available maximum PV power without utilizing an input electrolytic capacitor. Further, the operation of the presented system in continuous conduction mode (CCM) helps in reducing pulsations in current and thus it ensures continuous supply for motor pump operation. In order to enhance the power density of micro-inverters, multi-input DC-DC converters were proposed in (S. M. Tayebi, 2018), with the aim to connect multiple power sources (Z. Qian, 2010a, 2010b; H. AlAtrash, 2006). However, the proposed topologies were derived from non-isolated Cuk, buck-boost, single-ended primary-inductor converter (SEPIC), and Zeta converters (A. Kwasinski, 2009; Y. Li, 2010; H.Wu, 2013) and therefore are categorized under non-isolated configurations and are not useful in applications where isolation is required.

Different types/configurations of non-isolated DC-DC converters like SEPIC, Cuk, Zeta, Luo, etc. for maximum power extraction have been investigated and analyzed in the literature, however, applications of theses converters for high voltage applications is limited (Gajraj, 2016; R. Kumar, 2014a; 2014b; 2014c).

In smaller PV power applications like water pumping systems, where PV panels are connected in parallel to fulfill the current needs of the motor pump system, high voltage gain DC-DC converting stage is essential to step up low voltages (20-24 V) into usable high voltage (380 V) (R. J. Wai, 2007). Such converters require a high DC gain, high efficiency, and a wide operating input voltage range. Operation of DC-DC converters at high switching frequency results in reduced component size, less ripples, and high switching losses.

Further, to reduce high switching frequency losses, resonant converter topologies are useful as they reduce losses by ensuring zero current switching (ZCS) or zero voltage switching (ZVS) of power semiconductor components. Authors (A. Kumar, 2018), had discussed series-parallel resonant and 
series, parallel converters, and compared their performances. It was concluded that a wide range of switching frequency is required to obtain desired output voltage values and which results in the lossy magnetic design. LLC resonant and series LCL converters overcome the limitations of conventional DC-DC resonant converter configurations (A. Awasthi, 2018). LCL resonant converters are capable of providing high voltage gain along with good control over a wide range of output voltage despite variations in input voltage levels and connected loads. Further, when resonant tanks are integrated with a high-frequency transformer core, results in isolated, high voltage gain, compact design, a DC-DC converter with low losses.

An LLC converter has high operational efficiency of 97\% (T. Jiang, 2015) as compared to a conventional DC-DC boost converter with an efficiency of approx. 90\%. Also, the compact design of the LLC resonant converter makes them more compact and easier to handle. Considering the various advantages of the LLC DC-DC converter it is concluded as a popular choice among various other available converter topologies (Chub, 2017). PV based water pumping systems available in the literature are more focused on the extraction of maximum power from PV panels, less operational cost, less maintenance requirement, and most of the available configurations are based on the nonisolated type of DC-DC converter. In such an application DC bus voltage level generally vary between $500 \mathrm{~V}-700 \mathrm{~V}$ depending upon the type of motor-pump configuration used (A. Tomar, 2017). Such a high DC voltage level may result in unsafe operation as many times family members of farmers may operate the system and those personals may not be aware of operational safety and precautions.

In this paper, an LLC resonant DC-DC converter-based PV water pumping system is proposed considering human safety as a prime objective along with efficient utilization of available PV energy. As the considered system is isolated from the main grid and is operating with no storage element, therefore another objective is to maintain the rated RPM of the BLDC motor as close as possible to the rated value, with available PV.

The main contribution of the proposed work is as follows:

- Isolated DC-DC converter topology is applied to PV based water pumping system which makes its operation safer for humans.

- The application of the LLC resonant converter increases the power density and reduces the size of components.

- LLC resonant converter is up to $97 \%$ efficient as compared to conventional buck-boost converters. Therefore, their application in the proposed system will contribute to higher operating efficiency.

The paper is structured as follows: introduction along with a brief background of the problem statement is included in section I. Section II illustrates system description, component details, and control strategy for the proposed LLC converter-based PV water pumping system. Modeling and design of an LLC resonant converter is presented in section III. The performance of the proposed system is evaluated in the MATLAB/Simulink environment and results are discussed in section IV. Further, section $\mathrm{V}$ concludes the main findings and limitations of the proposed work.

\section{SYSTEM DESCRIPTION \& CONTROL ARCHITECTURE}

In this section description of the proposed LLC converter-based PV water pumping system configuration along with details of its control structure is presented. Figure 1 depicts the schematic of the proposed system with control architecture. The proposed system consists of arrays of PV modules that act as a source of energy for a complete water pumping system. No storage system is considered in the proposed architecture and it operates in standalone mode only (no access to grid electricity). Various series and parallel configurations of PV modules are possible to address the voltage and current demands of the connected load. Brushless DC motor (BLDC) and centrifugal pump act as the loads to the system. PV system is connected with the load through LLC resonant 


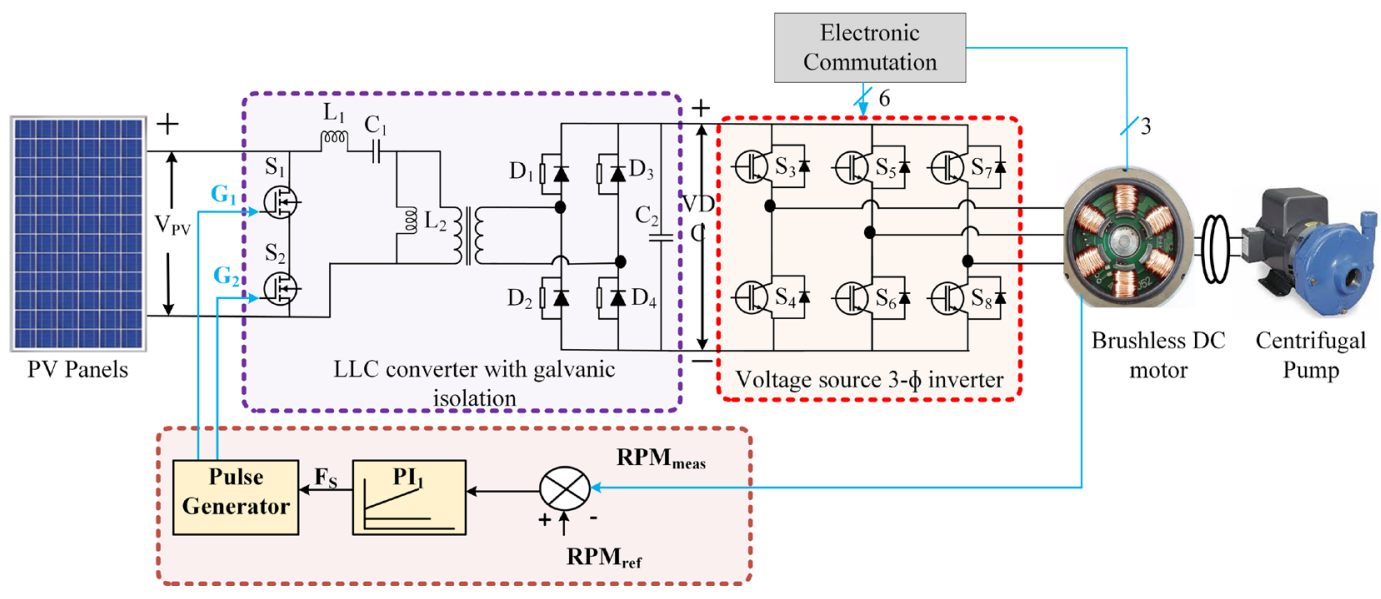

DC-DC converter and the voltage source inverter (VSI). The overall capacity of a PV system is considered as $1.5 \mathrm{~kW}$ under standard test conditions (STC) considering an area of $37.5 \mathrm{~m}^{2}$ for PV installations and conversion efficiency of $13 \%$ for PV panels. BLDC motor pump has a capacity of $1.2 \mathrm{~kW}$ and 3000 as rated RPM. As the proposed system is without any storage element and other sources of energy, the objective here is optimally utilizing the available PV power and try to maintain the actual operational RPM of the motor, close to the rated value.

LLC resonant DC-DC converter with galvanic isolation is considered in the proposed configuration (Figure 1) to consider the safety of the human person as the main aim of the design perspective. LLC converter will enhance the safety aspects (as an isolated topology), increase the power density, and reduce the component size and switching losses. However, this all will come at an additional system implementation cost. This increased system cost is justified considering the safety aspects and higher efficiency of the LLC converter. PV panels will act as an energy source for the LLC converter and it will convert the output voltage of the PV panels to a level of voltage level, to maintain the rated RPM value of the motor i.e. voltage level at the output of LLC converter will purely depend upon the reference RPM value.

Output DC energy of LLC converter serves as an input to VSI which converts it into ac output and further utilizes this converted energy to feed the BLDC motor-pump system. Electronic commutation of BLDC motor supported by its built-in encoder is utilized for the operation of VSI at the fundamental switching frequency. Thereby, limiting the high-frequency switching losses and thus supporting the energy-efficient operation of the proposed system. More details on the control of BLDC motor can be referred from available literature in (S. A. K. Mozafari Niapoor, 2010). The difference between the reference RPM and measured RPM values serves as an error signal for the proportional and integral controller $P I_{1}$ as shown in Figure 1. $F_{S}$ is the reference switching frequency which serves as a reference for pulse width generator. The minimum and maximum range of switching $F_{S}$ is considered as $40 \mathrm{kHz}$ to $120 \mathrm{kHz}$. However, further, an optimized range could be considered, to find the optimum balance. Application of maximum power point tracking (MPPT) control in PV water pumping applications without storage elements will not be useful as in the absence of storage devices as the extraction of power from PV would solely depend upon the active load of motor-pump system (A. Tomar, 2016). 


\section{Modelling of LLC DC-DC Converter System}

In this section, the modeling and design of the LLC resonant DC-DC converter is presented. As depicted in Figure 1, $L_{1}$ represents the resonant inductor, $L_{2}$ as a magnetizing inductor, and $C_{1}$ representing the resonant inductor. The selection of optimum LLC converter parameters for achieving higher efficiency is a tedious, challenging, and repetitive task.

As per the available literature, the selection of $L_{2}$ could be a more useful task, as it contributes to achieving zero voltage switching and thus reducing switching losses. To ensure soft-switching sufficient amount of current should be maintained in the resonant tank before the power semi-conductor switch turns off and its complementary switch becomes turned on. The drain to source capacitance $C_{1 S}$ (effective capacitance on the turning on the MOSFET) must be sufficiently charged and discharged by the no-load current $I_{1}$ which can be represented as follows:

$$
I_{1}=C_{1 s} S \frac{V_{P V}}{T_{d}}
$$

Here $S$ represents the number of MOSFETs in the circuit, $V_{P V}$ is the voltage across PV arrays which acts as the input voltage across the resonant tank, and the difference in the dead time of upper and lower MOSFET is depicted as $T_{d}$

Under resonance condition, $C_{1}$ and $L_{1}$ will be in series with effectively zero impedance and will result in $I_{1}$ in the sinusoidal waveform. Therefore, the upper limit on $L_{2}$ can be obtained as follows:

$$
L_{2}=\frac{V_{P V}}{4 f_{r} I_{1}}=\frac{T_{d}}{4 f_{r} C_{1 S} S}
$$

Due considerations and careful measures are required while applying the equations (1) and (2) in the design process. In order to calculate the dead time $T_{d}$, driving signal propagation time, the fall time, and turn-off delay time must be taken into consideration. These considerations are important due to the characteristics of the MOSFET and associated driving circuit. A slight difference in the actual and calculated value of $T_{d}$ is possible.

The voltage gain $G_{V}$ can be calculated as follows (Anjana, Sindhura, Tarun, \& Sujith, 2017; Mehna \& Chauhan, 2018):

$$
\frac{V_{1}}{V_{P V}}=\frac{j \cdot \omega_{n}^{2} \cdot K}{j \cdot\left(1+K-\frac{1}{\omega_{n}^{2}}\right)+K \cdot\left(1-\omega_{n}^{2}\right) \cdot Q}
$$

where $\omega_{n}$ depicts the ratio of resonant frequency and switching frequency, $K=L_{l} / \mathrm{L}_{2}, Q$ represents the quality factor.In equation (3), the frequency element can be eliminated, and the equation can be re-written in the form of equation (4) to obtain the maximum value of the quality factor $Q_{M}$. 


$$
Q_{M}=\frac{1}{K \cdot G_{M}} \sqrt{K+\frac{G_{M}^{2}}{G_{M}^{2}-1}}
$$

Further, the values of $L_{1}$ and $C_{1}$ can be derived from the pre-selected resonant frequency $f_{r}$ and inductance ratio $K$ :

$$
\begin{aligned}
& L_{1}=\frac{L_{2}}{K} \\
& C_{1}=\frac{L_{1}}{{Q_{M}{ }^{2} \cdot R_{e q}{ }^{2}}^{2}}
\end{aligned}
$$

As a result of the above, the switching frequency $f_{s}$ for isolated LLC DC-DC converter can be obtained:

$$
f_{s}=\frac{f_{r}}{\sqrt{1+k \cdot\left(1-\frac{1}{G^{2}}\right)}}
$$

\section{Selection of Centrifugal Pump}

The torque-speed characteristics are studied in order to investigate the value of the proportionality constant, $k$ (R. Kumar, 2014a). The load torque offered by the centrifugal pump can be stated as:

$$
T_{L}=k \omega^{2}
$$

where $T_{L}$ represents the load torque presented by the centrifugal pump; $\omega^{2}$ is defined as the mechanical speed of the rotor in rad./sec.

For the considered BLDC motor in this work $N_{\text {rated }}=9.2 \mathrm{Nm}$. Therefore, the proportionality constant $k$ could be stated as follows:

$$
k=\frac{T_{L}}{\omega_{r}^{2}}=\frac{9.2}{\left(2 \pi * \frac{R P M}{60}\right)^{2}}
$$

The centrifugal based on the above parameters is selected. 
Figure 2. Comparison among desired and measured value for motor RPM for variation in irradiance

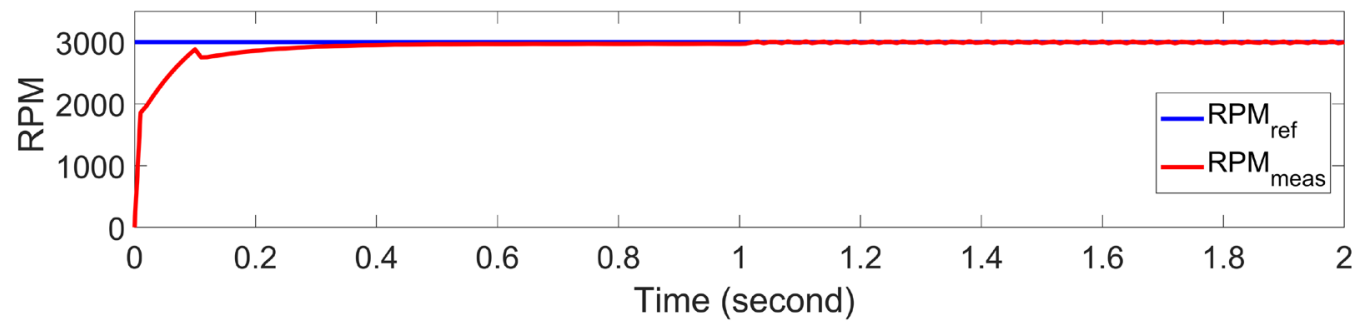

\section{SIMULATION RESULTS AND ANALYSIS}

The proposed LLC DC-DC converter-based PV water pumping system as per Figure 1 is investigated, simulated in MATLAB/Simulink environment and the results thus obtained are illustrated in this section. The objective of the control is to maintain the reference RPM value of the BLDC motor as close as possible to the reference or rated value; despite the change in irradiation levels.

Initially, irradiation is considered as $800 \mathrm{~W} / \mathrm{m}^{2}$ and at $\mathrm{t}=1$ second irradiation is increased by 100 $\mathrm{W} / \mathrm{m}^{2}$. Variation in the measured RPM value and the reference value is shown in Figure 2. Despite the increase in irradiance value at $\mathrm{t}=1$ second, the BLDC motor pump RPM value is maintained at 3000 RPM which is equal to the rated RPM of the BLDC motor in the proposed work. An increase in irradiation results in an increase in available PV power for the BLDC motor pump system, however, power transfer must be regulated such that to maintain the desired operation of the BLDC motor at RPM.

Figure 3 depicts the extracted PV power $P_{P V}$ and power being extracted at DC bus. Here, it is interesting to note that despite an increase of irradiation at $\mathrm{t}=1$ second, the power being extracted by the proposed system is regulated to $1.2 \mathrm{~kW}$, as per the rated power requirement of the BLDC motor pump system, in order to maintain the rated RPM as shown in Figure 2. Due to the increase in irradiance level at $\mathrm{t}=1$ second, the voltage across the PV array $V_{P V}$ increased, as shown in Figure 4. However, DC bus voltage is maintained as constant for the smooth operation of the water pumping system. Respective current variations are shown in Figure 5.

Further, Figures 6-7, depicts the inverter voltage $V_{a b}$ (voltage across phase 'a' and 'b' on BLDC inverter) and inverter current $I_{i n v}$ respectively. Variation in stator current is captured in Figure 8. As seen in Figure 6, the inverter phase voltage is being maintained by inverter control. LLC converter control maintained the constant, stable voltage at the DC bus along with the availability of sufficient energy for inverter control action. 
International Journal of Agricultural and Environmental Information Systems

Volume 12 •Issue 4 • October-December 2021

Figure 3. Power variation with change in irradiance

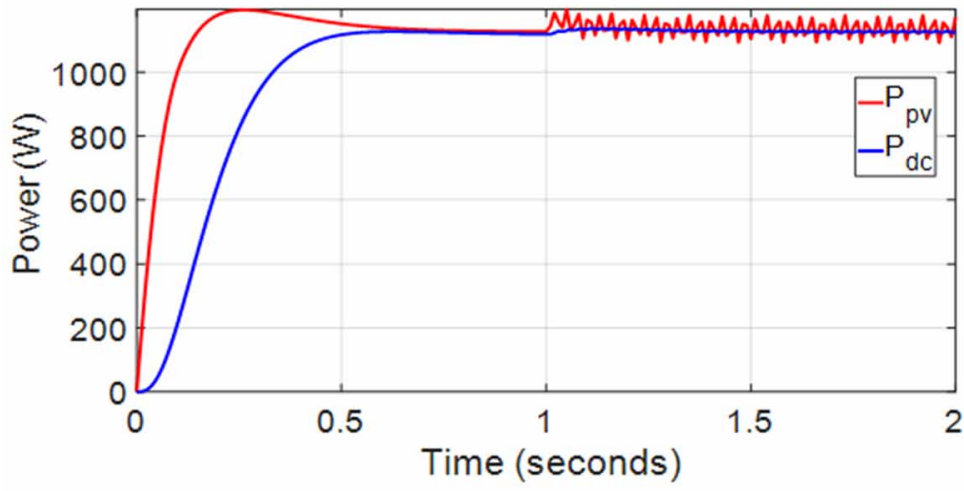

Figure 4. Voltage variation with irradiance change

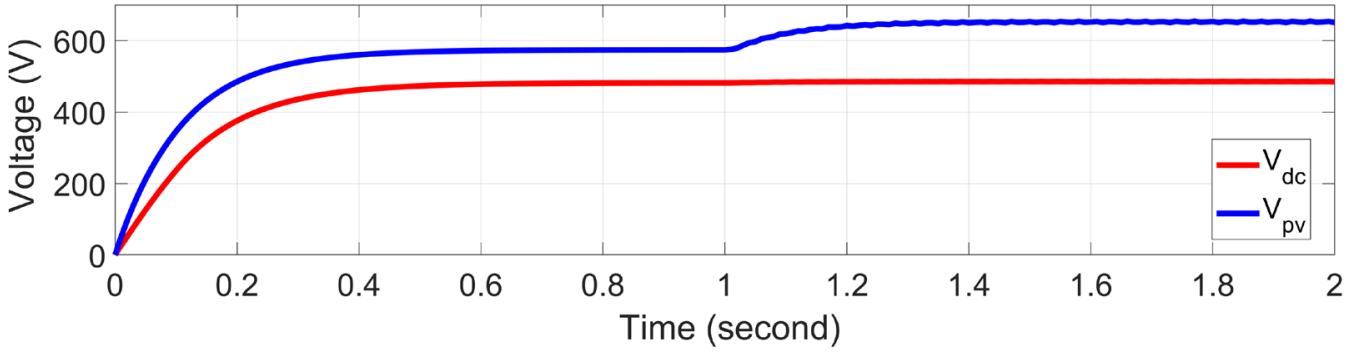

Figure 5. Variation in PV and DC bus current with irradiance change

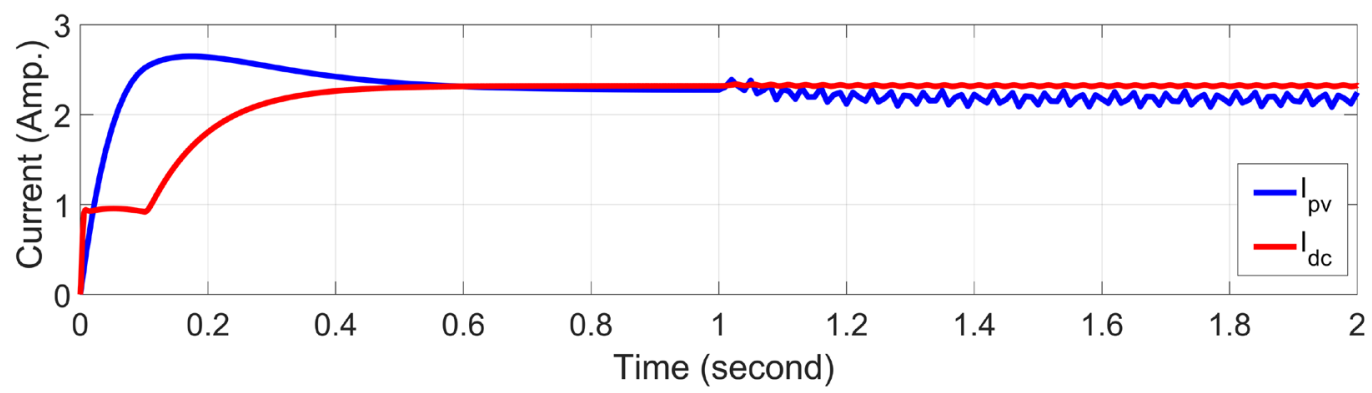


Figure 6. Variation in inverter voltage $\mathrm{V}_{\mathrm{ab}}$ with time

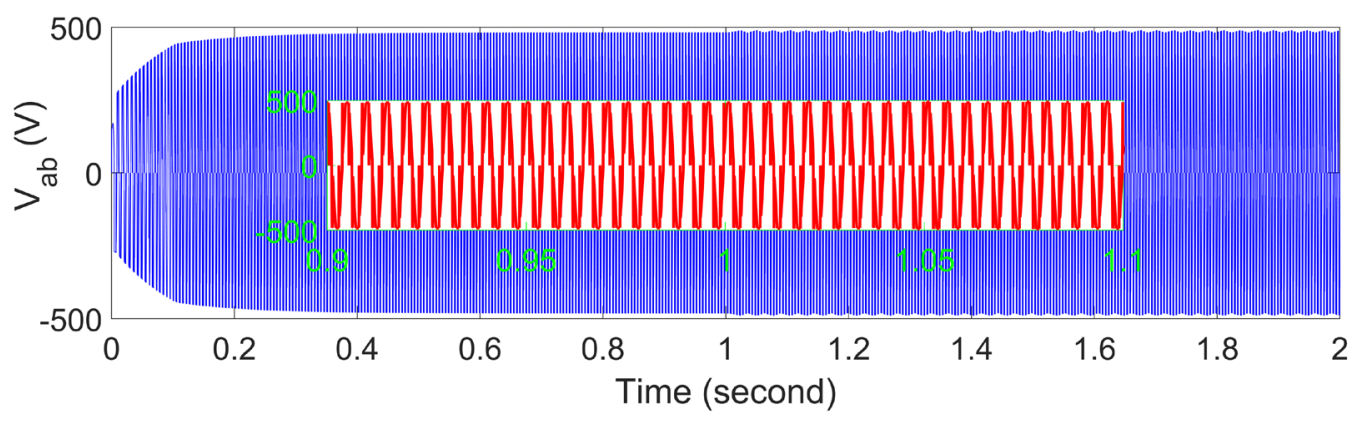

Figure 7. Variation in inverter output current $I_{i n v}$ (for phase 'a') with time

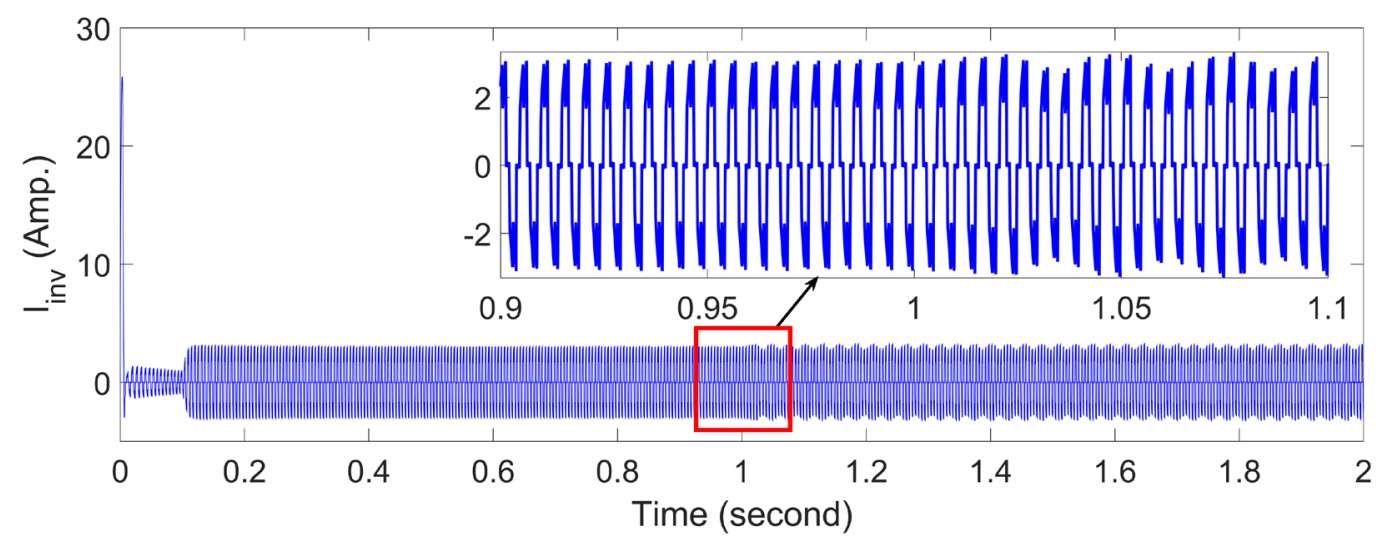


Figure 8. Variation in stator current $I_{a}$ with a change in irradiance

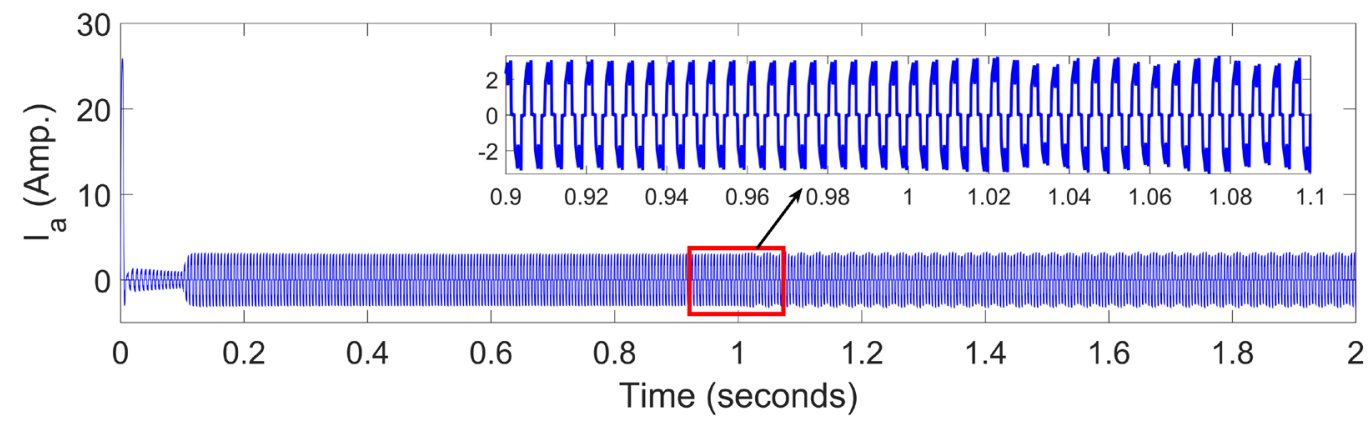

\section{CONCLUSION}

PV based water pumping system is an important application of solar PV and serves as a useful source of water for irrigation, drinking, and to serve the daily needs in remote/rural areas. The human's safety should be a prime concern while designing such systems, as these are primarily being operated by less skilled persons. On the contrary, the majority of the available PV based water pumping systems are based on non-isolated DC-DC converter topology and this results in less safe operating conditions. In this paper, an LLC converter-based PV water pumping system is introduced, which is based on non-isolated topology and thus a safer option for such systems. However, this additional safety comes at an additional system cost, but that could be compensated by relatively small component sizes; due to high-frequency switching operation. Simulation results show the satisfactory performance of the proposed system and the effectiveness of the LLC converter control to maintain the desired RPM of the BLDC motor. Proposed work could be useful for industrial productions (as a product in the market), after rigorous real-field experimentations, further improvements, and optimization in system design. 


\section{REFERENCES}

Al-Atrash, H., Pepper, M., \& Batarseh, I. "A Zero-Voltage Switching Three-Port Isolated Full-Bridge Converter," INTELEC 06 - Twenty-Eighth International Telecommunications Energy Conference, 2006, pp. 1-8, doi: doi:10.1109/INTLEC.2006.251647

Anjana, A. R., Sindhura, M., Tarun, C. H., \& Sujith, M. (2017). Solar powered luo converter fed three phase induction motor for water pumping system. 2017 International Conference on Inventive Systems and Control (ICISC), 1-5. doi:10.1109/ICISC.2017.8068672

Awasthi, A., Bagawade, S., Kumar, A., \& Jain, P. (2018). An Exact Time Domain Analysis of DCM Boost Mode LLC Resonant Converter for PV applications. IECON 2018 - $44^{\text {th }}$ Annual Conference of the IEEE Industrial Electronics Society, 1005-1010. doi:10.1109/IECON.2018.8591854

Caracas, J. V. M., Farias, G. C., Teixeira, L. F. M., \& Ribeiro, L. A. S. (2014, January-February). Implementation of a High-Efficiency, High-Lifetime, and Low-Cost Converter for an Autonomous Photovoltaic Water Pumping System. IEEE Transactions on Industry Applications, 50(1), 631-641. doi:10.1109/TIA.2013.2271214

Chub, D., Vinnikov, D., Kosenko, R., \& Liivik, E. (2017). Wide Input Voltage Range Photovoltaic Microconverter with Reconfigurable Buck-Boost Switching Stage. IEEE Transactions on Industrial Electronics, 64(7), 59745983. doi:10.1109/TIE.2016.2645891

Gajraj, Chauhan, \& Kumar. (2016). Indirect back EMF detection based sensorless operation of PMBLDC motor drive. IEEE 1st International Conference on Power Electronics, Intelligent Control and Energy Systems (ICPEICES), 1-5.

Gali, V., \& Amrutha, P. B. (2016). Fast dynamic response of SEPIC converter based photovoltaic DC motor drive for water pumping system. 2016 International Conference on Circuit, Power and Computing Technologies (ICCPCT), 1-5. doi:10.1109/ICCPCT.2016.7530298

Jayaraj, T., \& Justin Sunil Dhas, G. (2019). KY Based DC-DC Converter for Standalone Photovoltaic Water Pumping System Employing Four Switch BLDC Drive. 2019 Fifth International Conference on Electrical Energy Systems (ICEES), 1-6. doi:10.1109/ICEES.2019.8719316

Jiang, T., Zhang, J., Wu, X., Sheng, K., \& Wang, Y. (2015, February). A Bidirectional LLC Resonant Converter With Automatic Forward and Backward Mode Transition. IEEE Transactions on Power Electronics, 30(2), 757-770. doi:10.1109/TPEL.2014.2307329

Kumar, A., Singh, R. K., \& Naick, B. K. (2018). A Highly Efficient PV and Fuel Cell Powered Full Bridge Bidirectional LLC Resonant Converter. International Electrical Engineering Congress (iEECON), 1-4. doi:10.1109/IEECON.2018.8712288

Kumar, R., \& Singh, B. (2014). Buck-boost converter fed BLDC motor drive for solar PV array based water pumping. 2014 IEEE International Conference on Power Electronics, Drives and Energy Systems (PEDES), 1-6. doi:10.1109/PEDES.2014.7042001

Kumar, R., \& Singh, B. (2014). Solar PV array fed water pumping system using SEPIC converter based BLDC motor drive. Eighteenth National Power Systems Conference (NPSC), 1-5. doi:10.1109/NPSC.2014.7103820

Kumar, R., \& Singh, B. (2014). Solar PV array fed water pumping system using SEPIC converter based BLDC motor drive. 8th National Power Systems Conference (NPSC), 1-5. doi:10.1109/NPSC.2014.7103820

Kumar, R., \& Singh, B. (2014). Solar PV Array Fed Cuk Converter-VSI Controlled BLDC Motor Drive for Water Pumping. 6th IEEE Power India International Conference (PIICON), 1-7.

Kumar, R., \& Singh, B. (2014). Buck-Boost Converter Fed BLDC Motor Drive for Solar PV Array Based Water Pumping. IEEE International Conference on Power Electronics, Drives and Energy Systems (PEDES), 1-6. doi:10.1109/PEDES.2014.7042001

Kumar, R., \& Singh, B. (2016). BLDC Motor-Driven Solar PV Array-Fed Water Pumping System Employing Zeta Converter. IEEE Transactions on Industry Applications, 52(3), 2315-2322. doi:10.1109/TIA.2016.2522943

Kwasinski, A. (2009, March). Identification of feasible topologies for multiple input dc-dc converters. IEEE Transactions on Power Electronics, 24(3), 856-861. doi:10.1109/TPEL.2008.2009538 
Li, Y., Ruan, X., Yang, D., Liu, F., \& Tse, C. K. (2010, September). Synthesis of multiple input dc/dc converters. IEEE Transactions on Power Electronics, 25(9), 2372-2385. doi:10.1109/TPEL.2010.2047273

Meghna \& Chauhan. (2018). PV Water Pumping Using Integrated Quadratic Boost Zeta Converter. International Conference on Power Energy, Environment and Intelligent Control (PEEIC), 120-125. doi:10.1109/ PEEIC.2018.8665640

Mishra, A. K., Singh, B., Chandra, A., \& Al-Haddad, K. (2017). A novel modified central switch DC-DC converter for solar energized SRM driven irrigation pump. 2017 AEIT International Annual Conference, 1-6. doi:10.23919/AEIT.2017.8240535

Mozafari Niapoor, S. A. K., Danyali, S., \& Sharifian, M. B. B. (2010). PV power system based MPPT Z-source inverter to supply a sensorless BLDC motor. In $20101^{\text {st }}$ Power Electronic \& Drive Systems \& Technologies Conference. PEDSTC., doi:10.1109/PEDSTC.2010.5471845

Qian, Z., Abdel-Rahman, O., Al-Atrash, H., \& Batarseh, I. (2010, March). Modeling and control of three-port $\mathrm{dc} / \mathrm{dc}$ converter interface for satellite applications. IEEE Transactions on Power Electronics, 25(3), 637-649. doi:10.1109/TPEL.2009.2033926

Qian, Z., Abdel-Rahman, O., \& Batarseh, I. (2010, July). An integrated four-port dc/dc converter for renewable energy applications. IEEE Transactions on Power Electronics, 25(7), 1877-1887. doi:10.1109/ TPEL.2010.2043119

Shah, K., Krishnasamy, V., \& Neeli, S. (2017). Sliding mode assisted MPPT technique using quadratic boost converter for solar PV based DC water pumping system. 2017 International Conference on Intelligent Computing and Control (I2C2), 1-5. doi:10.1109/I2C2.2017.8321961

Singh, B., \& Mishra, A. K. (2018). PV Array Energized Standalone Water Pumping System Using Dual Output SE-CuCC Converter. IECON 2018 - 44th Annual Conference of the IEEE Industrial Electronics Society, 14241429. doi:10.1109/IECON.2018.8591690

Tayebi, S. M., Hu, H., Abdel-Rahman, S., \& Batarseh, I. (2019, March-April). Dual-Input Single-Resonant Tank LLC Converter with Phase Shift Control for PV Applications. IEEE Transactions on Industry Applications, 55(2), 1729-1739. doi:10.1109/TIA.2018.2883015

Tomar \& Mishra. (2017). Synthesis of a New DLMPPT Technique With PLC for Enhanced PV Energy Extraction Under Varying Irradiance and Load Changing Conditions. IEEE Journal of Photovoltaics, 7(3), 839-848. $.10 .1109 /$ JPHOTOV.2017.2675979

Tomar, A., \& Mishra, S. (2016). Multi-input single-output DC-DC converter based PV water pumping system. 2016 IEEE 1st International Conference on Power Electronics, Intelligent Control and Energy Systems (ICPEICES), 1-5. doi:10.1109/ICPEICES.2016.7853223

Vtas, P., \& Pal, Y. (2017). Solar PV array buck-boost converter fed single phase induction motor drives for water pumping. 2017 International Conference on Information, Communication, Instrumentation and Control (ICICIC), 1-5. doi:10.1109/ICOMICON.2017.8279090

Wai, R. J., Lin, C. Y., Duan, R. Y., \& Chang, Y. R. (2007, February). High-Efficiency DC/DC Converter With High Voltage Gain and Reduced Switch Stress. IEEE Transactions on Industrial Electronics, 54(1), 354-364. doi:10.1109/TIE.2006.888794

Wu, H., Sun, K., Ding, S., \& Xing, Y. (2013, July). Topology derivation of non-isolated three-port dc-dc converters from DIC and DOC. IEEE Transactions on Power Electronics, 28(7), 3297-3307. doi:10.1109/ TPEL.2012.2221746

Anuradha Tomar $(P h D)$ is currently working as Postdoc researcher in EES Group, Eindhoven University. She is associated with European Commission's Horizon 2020, UNITED GRID project as a team member. She is also associated as an Associate Professor with the Electrical Engineering Department at JSS Academy of Technical Education, Noida, India. She has received her B.E Degree in Electronics Instrumentation \& Control with Honours in the year 2007 from University of Rajasthan, India. In the year 2009, she has completed her M. Tech Degree with Honours in Power System from National Institute of Technology Hamirpur. She has completed her PhD in Electrical Engineering from Indian Institute of Technology Delhi in the year 2019. She has authored or co-authored 69 research/review papers in various reputed International, National Journals, and Conferences. Her research interests include photovoltaic systems, microgrids, energy conservation, and automation. She has also filled seven Indian patents on her name. Dr. Tomar is a Senior member of IEEE, ISTE, IETE, IEI, and IAENG. 